\title{
Direct antivirals and cognitive impairment in hepatitis C: a clinical-neurophysiologic study
}

\author{
Gloria Vaghi ${ }^{1} \cdot$ Benedetta Gori $^{2} \cdot$ Gionata Strigaro $^{2}$ (D) Michela Burlone ${ }^{1} \cdot$ Rosalba Minisini $^{1} \cdot$ Matteo N. Barbaglia $^{1} \cdot$ \\ Elena Brigatti ${ }^{2} \cdot$ Claudia Varrasi $^{2} \cdot$ Mario Pirisi $^{1} \cdot$ Roberto Cantello $^{2}$
}

Received: 19 May 2020 / Revised: 5 August 2020 / Accepted: 26 August 2020 / Published online: 10 September 2020

(C) The Author(s) 2020

\begin{abstract}
Cognition was assessed in hepatitis C virus (HCV) patients, who did not meet the criteria for a minimal hepatic encephalopathy. Their liver function was compensated. We then disentangled potential cognitive changes associated with a sustained virologic response at 12 weeks (SVR-12), following treatment with direct antiviral agents (DAAs). We studied 23 selected HCV patients with a battery of standard neuropsychological tests, and with recordings of the P300 wave, a cerebral potential of "cognitive" significance. There was a baseline evaluation (T0) and a second one 6 months later (T1). We had 2 control groups of comparable age and sex, i.e., 15 patients suffering from non-alcoholic fatty liver disease (NAFLD) and 15 healthy subjects. At T0, we detected a significant $(p<0.05)$ cognitive impairment in the HCV group, which involved episodic and working memory, attention, visuospatial and verbal abilities, executive functions, and logic reasoning. The P300 latency was significantly $(p<0.05)$ delayed in the group. At T1, we observed some significant $(p<0.05)$ HCV recovery in given test domains, e.g., memory, executive functions, and reasoning. Accordingly, the P300 latency shortened significantly $(p<0.05)$. HCV patients exhibited subtle cognitive defects, somehow independent of their liver condition, possibly linked to direct or indirect brain involvement by the virus. These defects partly recovered following the SVR-12, as achieved through DAAs. The P300 wave was a valid neurophysiologic counterpart of these changes. DAAs can have a role in the early preservation of cognition in HCVs.
\end{abstract}

Keywords Hepatitis C $\cdot$ Cognitive impairment $\cdot$ Neuropsychology $\cdot$ P300 wave $\cdot$ Direct antiviral agents

\section{Introduction}

Hepatic encephalopathy (HE) and its mildest expression (minimal HE) are a neuropsychiatric syndrome related to liver failure, with a wide range of severity (Wijdicks 2016). However, hepatitis $\mathrm{C}$ virus (HCV) patients not even meeting the definition(s) of minimal HE (Weissenborn 2015) can show a subtle cognitive impairment. This picture, also termed HCVassociated neurocognitive disorder (HCV-AND) affects for instance attention, executive functions, learning/visuospatial

Gloria Vaghi and Benedetta Gori contributed equally to this work.

Gionata Strigaro

gionata.strigaro@gmail.com;

gionata.strigaro@maggioreosp.novara.it

1 Internal Medicine Department of Translational Medicine, University of Piemonte Orientale, Novara, Italy

2 Neurology Unit Department of Translational Medicine, University of Piemonte Orientale, Novara, Italy abilities, and verbal recall. Its features are indeed different from minimal HE (Monaco et al. 2015). HCV infection can also imply fatigue and depression, and an overall reduced quality of life, which however have no clear relation to cognitive changes (Yeoh et al. 2018).

In the interferon era, several studies after HCV eradication showed improvement not only in quality of life or mood, but also in reaction time (Thein et al. 2007), verbal memory and visuospatial ability (Byrnes et al. 2012), and working memory (Kraus et al. 2013). However, sometimes there were biases such as HIV co-infection, substance abuse, or the neuropsychiatric side effects of peginterferon itself. Some authors questioned any actual improvement, and the whole topic is somehow controversial (Dirks et al. 2017).

Direct antiviral agents (DAAs) can lead to a sustained viral clearance in up to $96.8 \%$ of patients, as measured by the absence of HCV RNA sequences in the serum. They lack certain typical side effects of interferon, e.g., fatigue, (Pecoraro et al. 2019). So far, it is not firmly established if DAAs can relieve the HCV-AND syndrome. Some authors described a favorable outcome (Kleefeld et al. 2018), while others did not, or 
even envisaged some DAA neurotoxicity (Volpato et al. 2017).

We were thus prompted to (a) explore cognition in a selected $\mathrm{HCV}$ population not meeting the definition of minimal $\mathrm{HE}$ and (b) disentangle any possible cognitive change associated with a successful DAA cycle. To this aim, we combined a battery of standard neuropsychological tests to a recording of cerebral event-related potentials (i.e. the P300 wave). P300 is an "endogenous" brain wave associated with perceptual and cognitive activity. Its amplitude reflects the neural resources involved in a specific cognitive process, while its latency reflects the time course of that process, with a millisecond precision. Among various applications, P300 was thus proposed as a sensitive cognitive index in HCV patients (Kramer et al. 2002). Though not formally indicated for clinical use (Amodio and Montagnese 2015), it may "provide an insight into the cognitive processes in research settings" (Guerit et al. 2009). Recently, its usefulness was strongly revived (FathElbab et al. 2018). Therefore, we hypothesized that P300 would be quite appropriate an instrumental measure, to strengthen the neuropsychological findings expected before and after the DAA treatment.

\section{Methods}

\section{Subjects}

We recruited consecutive patients with $\mathrm{HCV}$ infection referred to the Hepatology Clinic of the University Department of Internal Medicine, "Maggiore della Carità" University Hospital, Novara, Italy, between March and November 2017. Inclusion criteria were (a) age $>18$ yearsold and (b) DAA treatment (a combination of agents from 3 drug classes: protease inhibitors, inhibitors of NS5A complex, and inhibitors of the RNA-dependent RNA polymerase; Appendix). Exclusion criteria were (a) drug abuse; (b) excess alcohol consumption, i.e., $>2 \mathrm{UA} /$ day for men and $>1 \mathrm{UA} /$ day for women between 18 and 65 years of age; $>1 \mathrm{UA} /$ day, above 65 years of age; (c) Child-Pugh-Turcotte score $\geq$ A7 (Child and Turcotte 1964); (d) central nervous system-CNS - or psychiatric symptoms/signs, particularly depression; (e) fatigue as a consistent complaint; (f) medications acting on the CNS; and (g) hearing loss. Initially, 62 patients met these criteria. However, 6 were rejected for language barriers; 28 did not consent to the study, and 5 were lost at follow-up. Twenty-three HCV patients thus completed the study (10 women, median age 66 years).

As control groups, we had 15 patients with NAFLD (6 women, median age 63 years), whose liver condition was meant to be comparable to the HCV group. We also had 15 HS ( 7 women, median age 60 years). Demography of controls was similar to HCVs. NAFLD diagnosis was made according to the following criteria: (a) finding of steatosis on liver biopsy, and/or of hyperechoic parenchyma on ultrasounds; (b) exclusion of excess alcohol consumption, as defined previously; (c) exclusion of alternative explanations for steatosis; and (d) exclusion of coexisting causes of chronic liver disease (Chalasani et al. 2018). Moreover, we excluded patients with neurologic/psychiatric symptoms/signs, particularly depression, and with fatigue as a predominant complain.

All subjects, whose IQ was in the normal range, gave their written informed consent to the study. Experiments were approved by the Ethics Committee of the "Maggiore della Carità" University Hospital (\# RQ07117), and were performed in accordance with the Declaration of Helsinki.

In principle, all subjects were examined twice, i.e., at baseline (time 0, T0) and 6 months later, i.e., when the 12-week SVR (Chen et al. 2013) of HCV patients had been properly documented (time 1, T1).

\section{Neuropsychology}

Assessment was conducted by a skilled neuropsychologist, blinded to the subject condition. An extensive test battery was used, which lasted approximately $70 \mathrm{~min}$. Global cognition was assessed by means of the Mini Mental State Examination (MMSE) (Folstein et al. 1975) and the Psychometric Hepatic Encephalopathy Score (PHES). PHES is a standardized battery ( 5 subtests) created to assess neuropsychological functions in patients with chronic hepatitis (Weissenborn et al. 2001). Additionally, verbal learning and episodic memory were tested using the Rey Auditory Verbal Learning Test (RAVLT, immediate and delayed) (Rey 1964). Episodic memory was also assessed by the Digit Forward Span, whereas the Digit Backward Span tested working memory (Wechsler 1958). The Rey-Osterrieth Complex Figure Test (ROCF) was used to evaluate visuospatial abilities/planning in the immediate trial, and episodic and working memory in the 10 -min delayed recall trial (Osterrieth 1944). Additional investigation of lexical abilities and executive functions was carried out with the Phonemic (Borkowski et al. 1967) and the Semantic Verbal Fluency tests (Marra et al. 2007). Finally, the verbal judgment test was used to assess logic thinking (Spinnler and Tognoni 1987).

\section{Neurophysiology: Auditory P300}

Studies were carried out between 2:00 and 6:30 p.m. at a standard temperature of $22^{\circ} \mathrm{C}$. Subjects lay comfortably in a dimly illuminated (= ca $30 \mathrm{Lux}$ ), partially soundproof room, with eyes open. Overall, we followed the guidelines reported by Duncan et al. (Duncan et al. 2009). The EEG signal was recorded by a $\mathrm{BE}$ Light digital machine connected to a multimodal stimulator (EB Neuro Corp., Florence, Italy). Ag/AgCl surface electrodes were attached to the scalp with adhesive 
electrolyte gel. Active sites were $\mathrm{Fz}, \mathrm{Cz}, \mathrm{Pz}, \mathrm{C} 4$, and C3 (10/ 20 International System), which were referred to averaged mastoids (M1-M2). Electro-oculogram (EOG) was also recorded by electrodes placed at the bilateral outer cantus. Impedance was maintained below $5 \mathrm{k} \Omega$. The filter bandpass was $0.05-100 \mathrm{~Hz}$. Artifacts were rejected automatically (i.e., when the EEG and the EOG amplitude exceeded $100 \mu \mathrm{V}$ ) via software. The sweep was $1000 \mathrm{~ms}$, with a prestimulus analysis of $150 \mathrm{~ms}$. Randomly intermixed standard $(80 \%, 1000 \mathrm{~Hz})$ and target $(20 \%, 2000 \mathrm{~Hz})$ tones were delivered binaurally by headphones at $70 \mathrm{~dB}$ SPL. The auditory stimuli lasted $100 \mathrm{~ms}$ (including $10 \mathrm{~ms}$ rise and fall times), while the inter-stimulus interval (ISI) varied randomly from 1500 to $2000 \mathrm{~ms}$. The first stimulus sequence was presented without instructions ("passive" odd-ball). Later, subjects were instructed to keep a mental record of the target tones and to report their number by the end of the run ("active" odd-ball). Forty-eight artifact-free EEG epochs following the target tones were finally averaged for both paradigms. For all averages, we then identified the P300 wave as the largest positive deflection between 250 and $600 \mathrm{~ms}$ after the stimulus onset. We also identified the N100 and N200 components in the time-windows between 60 and 150 and $150-300 \mathrm{~ms}$, respectively. By computer cursors, a neurophysiologist (blinded to subject condition) measured the N100, N200, and P300 latency, and the P300 amplitude as appreciated peak-to-peak (N200-P300), relative to the prestimulus baseline ( -150 to $0 \mathrm{~ms}$ ).

\section{Data analysis}

The statistical analysis was conducted with the SPSS software, ver. 25 (IBM Corp., USA). Almost all biometric/ biochemical variables did not show a normal distribution (Shapiro-Wilk test). After grouping, they were thus expressed as median values (25th-75th percentile). Differences among groups were then analyzed by Mann-Whitney $U$ tests, Wilcoxon signed-rank tests, or Kruskal-Wallis tests where appropriate. Categorical variables were expressed as frequencies (\% of total), and their associations were explored by the Pearson chi-square or Fisher exact tests, where appropriate. The neuropsychological and neurophysiological variables were expressed as mean values \pm standard error of the mean (SEM). Baseline (T0) values were compared among groups by means of one-way ANOVA. Comparisons between the $\mathrm{T} 0$ and $\mathrm{T} 1$ determinations were analyzed by means of repeated-measure ANOVA models. Where necessary, further ANOVAs and post-hoc Tukey HSD tests for multiple comparisons were used to detect differences among subgroups. Significance was set at $p<0.05$. Correlations between the variables measured were studied by means of Spearman's rho or Pearson's $r$ coefficients where appropriate.

\section{Results}

\section{Subject features}

No significant difference was detected among the groups for age, sex, and schooling. Considering patients with liver disease, the BMI and the albumin level were significantly (and blood glucose nearly significantly) higher in the NAFLD than in the HCV subgroup, while the reverse was true for AST and ALT measures (Table 1, also for $p$ values). The proportion of cirrhotic patients was ca $1 / 5$ (HCV group) and 1/3 (NAFLD group), which implied no significant difference. As far as HCV patients are considered, Table 2 shows the results of blood tests at T0 and T1. There was a significant $(p<0.001)$ improvement of some indexes of liver damage, i.e., AST and ALT, included a reduction in gamma-glutamyl transpeptidase (GGT) $(p<0.002)$.

\section{Neuropsychology}

TO In the HCV patient group, the mean scores on the MMSE, RAVLT, Digit Backward Span, Rey Figure Copy and verbal judgment tests were significantly worse than among HS. Then, if contrasted to the NAFLD group, HCV patients performed significantly worse on the PHES, the RAVLT, and the verbal judgment test, but also on the Rey Complex Figure Delayed and the Semantic Verbal Fluency tests. Interestingly, no significant difference emerged between NAFLDs and HS (Table 3, also for $p$ values).

T1 A preliminary three-way repeated-measure ANOVA examined the effect of the factors GROUP (HCV, NAFLD, HS), TIME (T0, T1), and TEST (each of the neuropsychological tests). This disclosed a significant GROUP*TIME*TEST within-subject interaction $(F=2.391, p<0.001)$. Thus, the average change (T1-T0) in the test scores was subject to a one-way ANOVA with post-hoc Tukey HSD comparisons among groups. This disclosed a significant improvement of the RAVLT and the verbal fluency scores (semantic and phonemic) in the HCV as compared with the NAFLD group. As to the verbal judgment test, its scores improved among HCVs in a manner that was close to statistical significance in comparison to NAFLDs, and significant in comparison to the HS subgroup (Table 4, also for $p$ values).

\section{Neurophysiology: auditory P300}

On a preliminary analysis, the latency of the "active" P300 was the sole variable to exhibit changes of interest. Thus, we will report solely about such index, as measured over the midline electrodes $\mathrm{Cz}, \mathrm{Fz}$, and $\mathrm{Pz}$, where the wave was best represented. 
Table 1 Main demographic, clinical, and biochemical features of the participants. Categorical variables are number $(\%)$, continuous variables are median values (25-75 percentile)

\begin{tabular}{|c|c|c|c|c|}
\hline \multirow[b]{2}{*}{ Variable } & \multicolumn{3}{|l|}{ Group } & \multirow[b]{2}{*}{$p^{*}$} \\
\hline & $\operatorname{HCV}(n=23)$ & NAFLD $(n=15)$ & HS $(n=15)$ & \\
\hline Age, years & $66.0(54.5-72.5)$ & $63.0(57.0-70.5)$ & $60.0(56.5-71.0)$ & 0.921 \\
\hline Women, $n(\%)$ & $10(43)$ & $6(40)$ & $7(47)$ & 0.934 \\
\hline Schooling, years & $10.0(7.50-12.0)$ & $9.0(8.0-11.5)$ & $13.0(8.00-13.0)$ & 0.287 \\
\hline Albumin, $\mathrm{g} / \mathrm{L}$ & $4.10(3.99-4.30)$ & $4.40(4.32-4.55)$ & & 0.036 \\
\hline ALP, U/L & $158(129-194)$ & $165(126-200)$ & & 0.950 \\
\hline ALT, U/L & $70.5(51.3-101)$ & $37(28-76)$ & & 0.030 \\
\hline $\mathrm{AST}, \mathrm{U} / \mathrm{L}$ & $55(34-79)$ & $29(23-37)$ & & 0.008 \\
\hline Bilirubin, mg/dl & $0.71(0.65-0.85)$ & $0.75(0.60-0.91)$ & & 0.987 \\
\hline GGT, U/L & $39(28-74)$ & $56(39-122)$ & & 0.162 \\
\hline Glucose, mg/dL & $87(85-93)$ & $97(91-118)$ & & 0.051 \\
\hline PLT, $/ \times 10^{3} \mathrm{uL}$ & $187(152-225)$ & 209 (188-219) & & 0.485 \\
\hline BMI, $\mathrm{kg} / \mathrm{m}^{2}$ & $24.8(21.7-27.2)$ & $27.3(26.00-31.8)$ & & 0.042 \\
\hline Cirrhosis, $n(\%)$ & $5(22)$ & $5(33)$ & & 0.476 \\
\hline HCV_RNA, UI/ml $\left(\times 10^{3}\right)$ & $474(214-1614)$ & & & \\
\hline \multicolumn{5}{|l|}{ HCV genotype, $n(\%)$} \\
\hline HCV-1a & $2(0.9)$ & & & \\
\hline $\mathrm{HCV}-1 \mathrm{~b}$ & $17(74)$ & & & \\
\hline $\mathrm{HCV}-2$ & $7(30)$ & & & \\
\hline $\mathrm{HCV}-3$ & $1(0.4)$ & & & \\
\hline $\mathrm{HCV}-4$ & $0(0)$ & & & \\
\hline Liver stiffness, $\mathrm{kPa}$ & $6.1(4.511 .4)$ & $8.8(6.0-14.0)$ & & 0.260 \\
\hline
\end{tabular}

$A L T$, alanine amino transferase; $A L P$, alkaline phosphatase; $A S T$, aspartate amino tsransferase; $B M I$, body mass index; $G G T$, gamma glutamyl-transpeptidase; $H C V$, hepatitis $\mathrm{C}$ virus patients; $H S$, healthy subjects; $N A F L D$, nonalcoholic fatty liver disease patients; $P L T$, platelets. *see methods, for the statistics used
T0 On a repeated-measure ANOVA, the dependent factor was SITE (i.e., $\mathrm{Cz}, \mathrm{Fz}$, and $\mathrm{Pz}$ ), and the independent factor was GROUP. No significant effect emerged for SITE, nor for the SITE*GROUP interaction $(p>0.05)$. Still there was a significant effect of GROUP $(F=3.429, p<0.04)$. On this basis, we

Table 2 Biochemical data in patients with chronic hepatitis $\mathrm{C}$ at baseline (T0) and 6 months later, i.e., at the time of the 12-week sustained viral response (T1). Variables are median values ( 25 th- 75 th percentile)

\begin{tabular}{lccr}
\hline HCV & & & \\
\hline Variable & T0 & T1 & $p^{*}$ \\
\hline Albumin, g/dL & $4.1(4.0-4.3)$ & $4.2(4.0-4.6)$ & 0.458 \\
ALP, U/L & $158(129-194)$ & $161(140-167)$ & 0.849 \\
ALT, U/L & $70.5(51.3-101)$ & $19(14.8-25.3)$ & $<0.001$ \\
AST, U/L & $55(34-79)$ & $21(20-32.5)$ & $<0.001$ \\
Bilirubin, mg/dl & $0.71(0.65-0.85)$ & $0.70(0.58-1.0)$ & 0.584 \\
GGT, U/L & $39(28-74)$ & $19(15-36)$ & 0.002 \\
PLT, $\times 10^{3 /} \mathrm{uL}$ & $187(152-225)$ & $207(178-248)$ & 0.250 \\
\hline
\end{tabular}

For abbreviations see Table 1. *see Methods, for the statistics used averaged for each subject the P300 latency values at all electrodes, which represented the dependent factor in a further one-way ANOVA where GROUP was the independent factor. This disclosed significant results $(F=3.432, p<0.04)$, while post-hoc Tukey HSD tests pointed out a significant difference between HCVs and NAFLDs $(p=0.04)$, while a similar trend was present between HCVs and HS $(p=0.1)$. NAFLDs and HS did not differ significantly (Table 5, Fig. 1). If all controls were grouped (NAFLD+HS), then the difference against HCVs was significant at the $p=0.03$ level.

T1 The P300 latency (average electrodes) at T0 and at T1 was the dependent factor in a repeated measure ANOVA, where the independent factor was GROUP. Here a significant interaction TIME*GROUP emerged $(F=3.543, p=0.04)$. Post-hoc tests revealed that the change T1-T0 distinguished the HCV from the other subgroups significantly $(p=0.03)$, since it exhibited a P300 shortening of about $15 \mathrm{~ms}$, which was lacking in the others (Table 5, Figs. 2 and 3a, b).

Correlations We found no significant correlation between any of the variables studied $(p>0.05)$. 
Table 3 Baseline (T0) psychometric assessment in the 3 groups (HCV, NAFLD, and HS). Test order is as administered. Data are mean \pm SEM. Groups were compared with a one-way ANOVA and between-group comparisons used Tukey HSD post-hoc contrasts

\begin{tabular}{|c|c|c|c|c|c|c|c|c|}
\hline \multirow[b]{2}{*}{ Test } & \multicolumn{3}{|l|}{ Group } & \multicolumn{2}{|c|}{ ANOVA } & \multicolumn{3}{|c|}{ Post-hoc comparisons $(p)$} \\
\hline & $\mathrm{HCV}(0)$ & NAFLD (1) & HS (2) & $\mathrm{F}$ & $p$ & 0 vs 1 & 0 vs 2 & 1 vs 2 \\
\hline MMSE & $28.4 \pm 0.29$ & $29.2 \pm 0.30$ & $29.6 \pm 0.36$ & 3.96 & 0.02 & - & 0.028 & - \\
\hline PHES & $-1.48 \pm 0.58$ & $0.53 \pm 0.44$ & $1.00 \pm 0.45$ & 6.74 & 0.003 & 0.027 & Not done & Not done \\
\hline RAVLT & $36.1 \pm 1.31$ & $42.2 \pm 1.66$ & $44.1 \pm 1.75$ & 8.05 & 0.001 & 0.019 & 0.002 & - \\
\hline RAVLT delayed & $7.91 \pm 0.43$ & $8.17 \pm 0.57$ & $8.65 \pm 0.68$ & 0.48 & 0.62 & - & - & - \\
\hline Digit Forward Span & $6.26 \pm 0.31$ & $6.73 \pm 0.27$ & $7.13 \pm 0.24$ & 2.36 & 0.105 & - & - & - \\
\hline Digit Backward Span & $3.70 \pm 0.28$ & $4.33 \pm 0.44$ & $5.07 \pm 0.32$ & 4.24 & 0.020 & - & 0.016 & - \\
\hline Rey Complex Figure Copy & $32.5 \pm 0.70$ & $34.6 \pm 0.50$ & $34.9 \pm 0.68$ & 3.97 & 0.025 & - & 0.044 & - \\
\hline Rey Complex Figure Delayed & $14.1 \pm 0.83$ & $18.3 \pm 1.47$ & $18.9 \pm 1.27$ & 4.54 & 0.015 & 0.033 & - & - \\
\hline Phonemic verbal fluency & $34.2 \pm 2.16$ & $36.8 \pm 2.64$ & $42.6 \pm 3.24$ & 2.67 & 0.08 & - & - & - \\
\hline Semantic verbal fluency & $17.5 \pm 0.86$ & $22.6 \pm 1.38$ & $21.5 \pm 1.65$ & 5.25 & 0.008 & 0.013 & - & - \\
\hline Verbal judgment test & $40.8 \pm 2.92$ & $50.4 \pm 1.67$ & $53.4 \pm 0.95$ & 8.30 & 0.001 & 0.018 & 0.001 & - \\
\hline
\end{tabular}

MMSE Mini Mental State Examination, PHES Psychometric Hepatic Encephalopathy Score, RAVLT Rey Auditory Verbal Learning Test

\section{Discussion}

At first, we meant to characterize the $\mathrm{HCV}$-associated neurocognitive disorder (AND) in a highly selected patient sample. To this aim, we compared the HCV psychometry and P300 wave to those of liver patients of equivalent severity, but different etiology (NAFLD), and to normal controls (HS). Selection criteria included, among others, the lack of alcohol or drug consumption, and of depressive symptoms/signs or chronic fatigue. Reportedly, HCV-AND is independent of mood or fatigue (Fortini et al. 2019). Yet, these variables could represent some undue source of bias. Demographic

Table 4 Changes in the neuropsychological tests between T1 and T0. After an omnibus repeated-measure ANOVA (see Results), average T1-T0 scores were subject to a one-way ANOVA, and between-group comparisons used post-hoc Tukey HSD contrasts

\begin{tabular}{|c|c|c|c|c|c|c|c|c|}
\hline \multirow[t]{2}{*}{ Test } & \multicolumn{3}{|c|}{ Score: T1-TO change } & \multicolumn{2}{|c|}{ ANOVA } & \multicolumn{3}{|c|}{ Post-hoc comparisons $(p)$} \\
\hline & $\mathrm{HCV}(0)$ & NAFLD (1) & $\mathrm{HC}(2)$ & $F$ & $p$ & 0 vs 1 & 0 vs 2 & 1 vs 2 \\
\hline MMSE & $\begin{array}{c}+0.08 \\
( \pm 0.37)\end{array}$ & $\begin{array}{c}+0.35 \\
( \pm 0.22)\end{array}$ & $\begin{array}{c}+0.33 \\
( \pm 0.21)\end{array}$ & 1.01 & 0.37 & - & - & - \\
\hline PHES & $+1.97( \pm 1.03)$ & $\begin{array}{l}+1.25 \\
( \pm 1.19)\end{array}$ & $\begin{array}{c}+2.70 \\
( \pm 1.16)\end{array}$ & 2.15 & 0.13 & - & - & - \\
\hline RAVLT & $\begin{array}{c}+8.00 \\
( \pm 1.32)\end{array}$ & $\begin{array}{c}+2.81 \\
( \pm 1.48)\end{array}$ & $\begin{array}{c}+4.22 \\
( \pm 1.32)\end{array}$ & 4.04 & 0.02 & 0.030 & - & - \\
\hline RAVLT delayed & $\begin{array}{l}+1.55 \\
( \pm 0.40)\end{array}$ & $\begin{array}{c}+0.87 \\
( \pm 0.48)\end{array}$ & $\begin{array}{l}+1.60 \\
( \pm 0.74)\end{array}$ & 0.54 & 0.59 & - & - & - \\
\hline Digit Forward Span & $\begin{array}{c}+0.22 \\
( \pm 0.19)\end{array}$ & $\begin{array}{l}+0.07 \\
( \pm 0.21)\end{array}$ & $\begin{array}{l}-0.13 \\
( \pm 0.22)\end{array}$ & 0.76 & 0.47 & - & - & - \\
\hline Digit Backward Span & $\begin{array}{c}+0.52 \\
( \pm 0.29)\end{array}$ & $\begin{array}{c}+0.33 \\
( \pm 0.27)\end{array}$ & $\begin{array}{c}-0.13 \\
( \pm 0.26)\end{array}$ & 1.39 & 0.25 & - & - & - \\
\hline Rey Complex Figure Copy & $\begin{array}{l}+0.89 \\
( \pm 0.91)\end{array}$ & $\begin{array}{c}+0.43 \\
( \pm 0.60)\end{array}$ & $\begin{array}{c}-1.42 \\
( \pm 0.69)\end{array}$ & 2.11 & 0.13 & - & - & - \\
\hline Rey Complex Figure Delayed & $\begin{array}{l}+1.98 \\
( \pm 1.03)\end{array}$ & $\begin{array}{l}+1.25 \\
( \pm 1.19)\end{array}$ & $\begin{array}{l}+2.70 \\
( \pm 1.16)\end{array}$ & 0.35 & 0.70 & - & - & - \\
\hline Phonemic verbal fluency & $+5.77( \pm 1.69)$ & $\begin{array}{c}-0.86 \\
( \pm 2.56)\end{array}$ & $+2.65( \pm 1.20)$ & 3.22 & 0.04 & 0.044 & - & - \\
\hline Semantic Verbal Fluency & $+2.93( \pm 0.91)$ & $-0.60( \pm 1.12)$ & $+0.80( \pm 1.13)$ & 3.31 & 0.04 & 0.041 & - & - \\
\hline Verbal judgment test & $+0.22( \pm 0.19)$ & $\begin{array}{c}+0.07 \\
( \pm 0.21)\end{array}$ & $-0.13( \pm 0.22)$ & 5.17 & 0.01 & 0.058 & 0.016 & - \\
\hline
\end{tabular}

Abbreviations: see Table 3 
Table 5 P300 latency measurement in the 3 subject groups. For the baseline determination (T0), separate values for the $\mathrm{Cz}, \mathrm{Fz}$, and $\mathrm{Pz}$ electrodes are shown, together with their average. Then the change T1-T0 among the groups is shown as the sole average

\begin{tabular}{lrrr}
\hline & \multicolumn{1}{l}{ Group } & \\
\cline { 2 - 4 } P300 latency (ms) & HCV & NAFLD & HS \\
\hline Baseline (T0) & & & \\
Cz & $357.1 \pm 5.0$ & $337.5 \pm 6.9$ & $341.2 \pm 7.6$ \\
Fz & $358.4 \pm 4.6$ & $337.4 \pm 6.9$ & $340.7 \pm 7.6$ \\
Pz & $358.2 \pm 4.9$ & $337.2 \pm 6.9$ & $341.6 \pm 7.6$ \\
Average 3 sites & $357.9 \pm 4.8$ & $337.4 \pm 6.9$ & $341.2 \pm 7.6$ \\
Change (T1-T0) Average 3 sites & $-15.3 \pm 5.4$ & $-0.56 \pm 0.6$ & $+0.52 \pm 2.1$ \\
\hline
\end{tabular}

Abbreviations: see Table 1 features and IQs were similar across groups, which warranted correct comparisons. Blood test findings were somewhat expected, based on the underlying pathology itself, particularly the AST/ALT enhancement in the HCV as compared with the NAFLD group. Liver function, as expressed by synthesis tests, was relatively preserved in both groups, where the proportion of cirrhotic patients was statistically similar, as was the amount of liver stiffness. Most patients thus suffered from compensated (mild-to-moderate) hepatic disease, with no between-group distinction at the baseline observation (T0). As for T1, we detected a significant lowering of AST/ALT and (to a lesser degree) GGT levels among HCVs. This was somehow expected, due to relieved cytolysis following virologic eradication (SVR-12).

As for neuropsychology at $\mathrm{T} 0$, a rather straight-forward finding was the lack of significant differences between NAFLDs and HS. This supports the view that a mild-to-moderate, compensated liver impairment, without $\mathrm{HCV}$ infection, would not produce any detectable cognitive defect. By contrast, HCV patients showed several differences in comparison with NAFLD and HS, which sometimes were significant against both, but sometimes against one or the other group. This apparent distinction may simply reflect a lack of

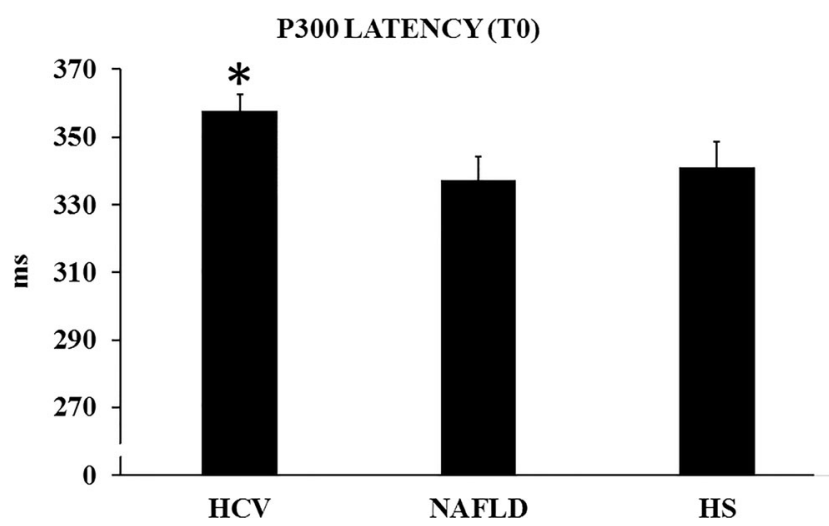

Fig. 1 Group values of the P300 latency (average of the $\mathrm{Cz}, \mathrm{Fz}$, and $\mathrm{Pz}$ electrodes) at $\mathrm{T} 0$ in the hepatitis $\mathrm{C}$ virus ( $\mathrm{HCV}$ ) and non-alcoholic fatty liver disease (NAFLD) patients, and in healthy subjects (HS). Bars represent standard error of the mean. $* p=0.04$ vs NAFLDs statistical power, due to the small sample size, and may not necessarily imply separate interpretations. Anyway, HCVs performed worse than both NAFLDs and HS on a test which explores episodic memory and learning abilities (RAVLT), and on another test, which assesses logic reasoning (verbal judgment). Then, there were differences between the HCV and the HS group on its own, which consisted of a poorer performance on the MMSE, a universal index of global cognition, and on a test which evaluates working memory, such as the Digit Backward Span. The same was true for the ROCF copy, which mainly explores visuospatial abilities, attention, (motor) planning, and working memory. Some tests finally distinguished HCVs from NAFLDs solely, since the former group did worse on the PHES battery, the gold-standard tool to evaluate cognition changes in the liver patient. Meanwhile, it must be stressed that the PHES score at T0 $(=-1.48$ in HCVs and $=0.53$ in NAFLDs) was far from the cutoff that defines a "minimal" hepatic encephalopathy $(=-4)$ (Weissenborn 2015). Moreover, HCVs had a poorer performance on the ROCF delayed test, which among others evaluates episodic memory, and on the Semantic Verbal Fluency test, which particularly quantifies the ability to access lexical

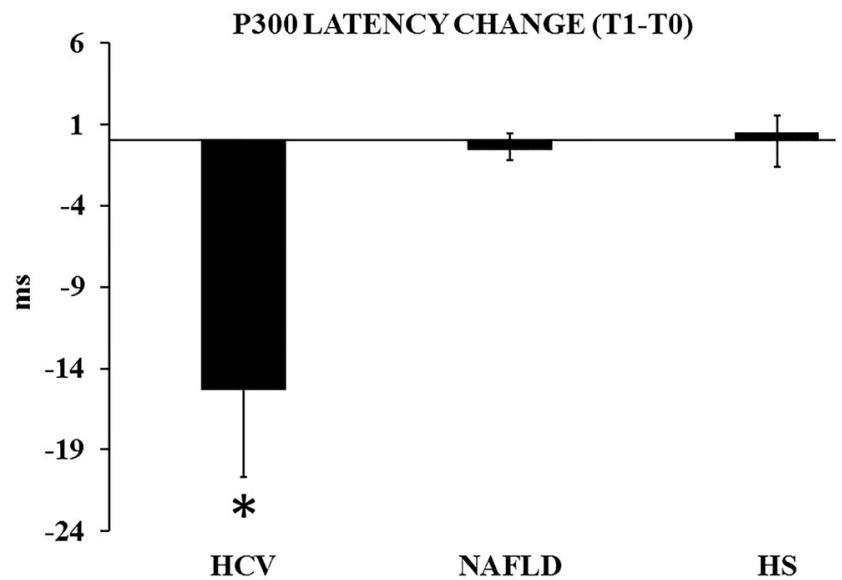

Fig. 2 Group values of the change (T1-T0) in the P300 latency (average of the $\mathrm{Cz}, \mathrm{Fz}$, and $\mathrm{Pz}$ electrodes) across the 3 subject populations. Abbreviations: see Fig. 1. Bars represent standard error of the mean. $* p=0.03$ vs NAFLDs and HCVs 
a

T0

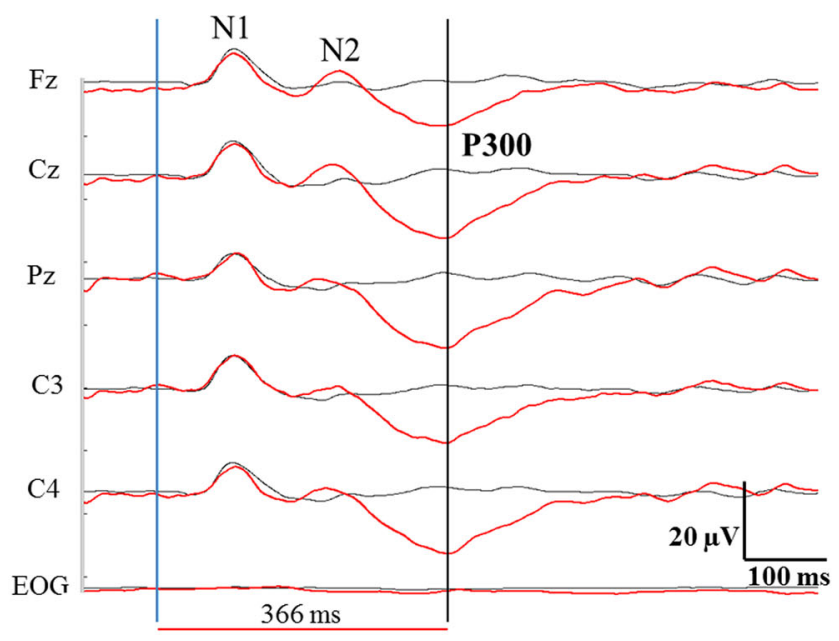

b

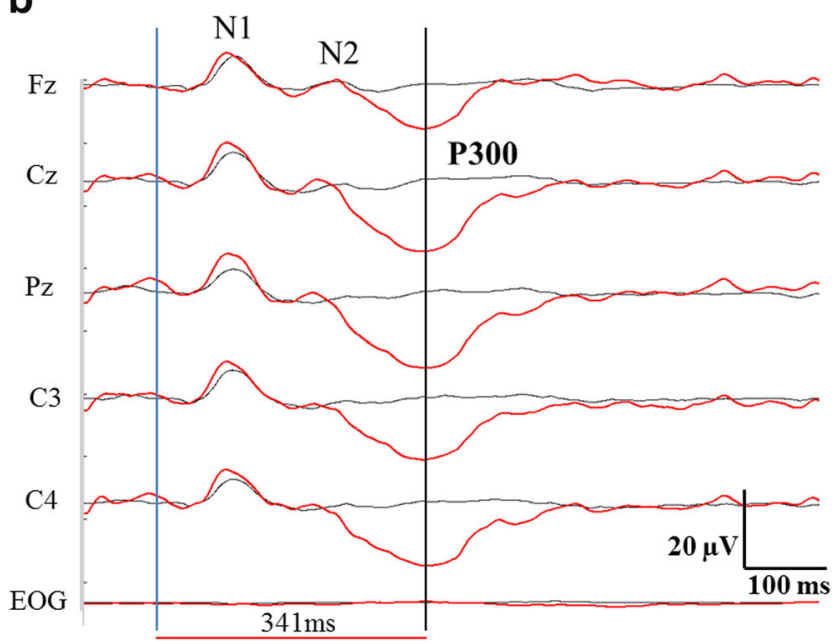

Fig. 3 a, b Typical example of a P300 recording in an HCV patient (\#15) prior (a) and after (b) the treatment with direct antiviral agents (T0 and T1). All electrodes were referred to averaged mastoids. Blue wave: averaged potential evoked by the standard stimulus. Red wave: averaged potential evoked by the oddball stimulus in the "active" paradigm. Blue vertical line: stimulus onset. Black vertical line: P300 latency, which shows a detectable shortening at T1. EOG Electrooculogram

resources. On the whole then, HCV patients were defective in a series of cognitive domains. This resembles previous reports since the early 2000s (Yarlott et al. 2017). HIV coinfection, alcohol/substance abuse, or high cirrhosis rate might have biased some of these studies (Monaco et al. 2015). However, they provided evidence of impaired verbal memory, attention, and psychomotor speed (Hilsabeck et al. 2002). Also, of defective executive functions (Diamond 2013), encompassing working memory, inhibition, and cognitive flexibility, as well as sustained attention (Lowry et al. 2010). Then, other authors found abnormalities in verbal learning (McAndrews et al. 2005) and verbal recall (Fontana et al.
2005; Lowry et al. 2010). Huckans et al. (Huckans et al. 2009), in a selected sample, reported an impairment of logic reasoning, which tallies the results of ours on the verbal judgment test.

At T0, we found a delayed P300 wave latency in the "active oddball" paradigm, which distinguished $\mathrm{HCV}$ s from NAFLDs significantly, and close to significance from HS. If both control groups were averaged, the difference attained a $p$ level $=0.03$. P300 is an event-related potential, having a nearly simultaneous latency over widespread cerebral regions. It may be generated by many independent sources, or by a "central integrated system" with a large cortical representation. P300 latency correlates with information processing speed (particularly stimulus categorization time), reaction time, and age (Picton 1992). This wave has been proposed as an early neurophysiologic marker of cognitive impairment in several neurological disorders, especially dementia (Duncan et al. 2009). It was also recommended in HCV patients with subclinical cognitive impairment, where it proved independent of depression, fatigue, or changes in the quality of life, and capable to overcome the inherent bias of neuropsychological batteries or the uncertainties of self-rating scales (Kramer et al. 2002). Later studies questioned the $P 300$ practical value in the clinical assessment of hepatic encephalopathy, since routine or quantitative EEG was found superior (Amodio et al. 2005). The International Society for Hepatic Encephalopathy and Nitrogen Metabolism (ISHEN) still preserved some role for the P300 in the research setting (Guerit et al. 2009). Most recently, the $P 300$ validity has been strongly revived by Fath-Elbab et al. (2018), since this index could disclose "minimal and subclinical impairment of cognitive function at early stages of chronic hepatitis with accuracy". Having controlled for confounding factors such age and alcohol consumption (Duncan et al. 2009), we thus value the P300 latency lengthening in HCVs as an objective counterpart of the subtle cognitive changes observed. Perhaps, supplementary EEG recordings would have been helpful, which is another limit of the present work. Yet, additional instrumental investigations were deemed to hamper the patient compliance.

Severity of liver involvement was equivalent among patients. Thus, the neuropsycho-physiological differences between HCVs and NAFLDs imply a responsibility of the viral infection, and its consequences. Besides, there are many evidences for a neurobiological origin of the HCV-AND, such as changes in the choline/creatinine or N-acetyl-aspartyl-glutamate/creatine ratios, or increased myoinositol, on proton magnetic resonance spectroscopy in various brain regions (Monaco et al. 2015). Some authors even found brain microstructural abnormalities using diffusion tensor MRI (Thames et al. 2015). HCV infection was associated with glial activation and increased myelin turnover. Viral particles and specific proteins were detected in given brain areas during HIV coinfection, and localized within cells of the astro- or microglial 
line (Letendre et al. 2007). Often, a neuroinflammatory neural response was envisaged, with a prominent role for cytokines (Yarlott et al. 2017). Moreover, aminergic transmission alterations were shown in HCV-AND patients by means singlephoton emission computerized tomography (SPECT) (Weissenborn et al. 2006). Similarly, fluorodeoxyglucose PET studies revealed metabolic abnormalities in several cortical regions (Heeren et al. 2011).

Secondly, we re-evaluated all subjects when HCVs had achieved their SVR-12 (T1). Here we relied on the premise that practice effects represented a systematic error across groups in the test-retest experimental design. On this assumption, we associate the SVR-12 with a significant cognitive improvement, limited to definite domains. This is the case for the functions tested by the RAVLT immediate test, i.e., predominantly short-term auditory-verbal memory, rate of learning, learning strategies, retroactive, and proactive interference. Then, changes in the Verbal Fluency support improvement in the access to lexical resources, as well as in cognitive flexibility and inhibitory control. These, in turn, represent key aspects of the "executive" machinery. Improvement of logic reasoning/thinking, as revealed by the verbal judgment test, would finally be in line with the previous effects. In the first place, such improvement may be related to better liver conditions, as shown by the decreased cytolysis. Other factors are however expected, since we previously showed that a mildly/moderately deranged liver function per se cannot justify cognitive changes. Then, one could invoke an overall improved quality of life, mood, or fatigue, which is somehow expected at the time of the SVR-12 (Juanbeltz et al. 2018). We do not report here these variables, which may represent another limit of the study, yet they were an exclusion criterion. Moreover, the HCV-AND would evolve as a separate entity (Dirks et al. 2017). Thus, a direct or indirect effect of the viral clearance onto the brain must be seriously considered.

The P300 latency showed a significant shortening at T1, which distinguished HCVs from the other subjects. This can reflect, in the first instance, the improved attentional and stimulus-processing abilities, which emerge by the psychometric assessment, as described previously. Particularly, the P300 latency mainly reflects the speed of the cognitive process involved in the experimental task (Duncan et al. 2009). To explain the P300 latency delay at T0, one must invoke the many neurobiological consequences of the $\mathrm{HCV}$ infection (detailed above). These may well impair the complex neural systems underlying the P300 physiology. In turn, viral eradication at $\mathrm{T} 1$ would consistently relieve such widespread functional impairment, reversing the P300 delay to a significant $(p=0.03)$ extent. From another perspective, the P300 change appears to strengthen, in an objective manner, the data obtained on clinical grounds. Possibly, further clinicalneurophysiologic evaluations at later time-points would have strengthened the findings, which we add to the study limits. Still, the present results somehow resemble those of Kleefeld et al. (2018). In a study of 22 patients, including HIVcoinfected subjects, these authors reported improvement in visual memory/learning, executive functions, verbal fluency, processing speed, and motor skills, on the achievement of SVR-12 after DAAs. Similarly, in the work by Hamdy et al. (2018), the sole Montreal Cognitive Assessment (MOCA) test was used to assess $62 \mathrm{HCV}$ patients, and beneficial effects were found at SVR-12. By contrast, Volpato et al. (2017) compared $10 \mathrm{HCV}$ patients with cirrhosis to 12 post-liver transplant HCVs. At the end of the DAA treatment, some worsening (on psychometry and EEG) emerged in the former, but not the latter group. At 6 months, this effect disappeared. No cognitive improvement by DAAs was however seen.

Unfortunately, we detected no significant correlations between the variables studied (demography, liver conditions, neuropsychology, and neurophysiology). This is possibly due to the lack of statistical power, which also rendered it unfeasible any data stratification, nor an analysis at the individual level.

\section{Conclusions}

Despite the limitations mentioned above, and considering the high patient selection, we confirm that HCV patients exhibit a peculiar type of subtle cognitive impairment (HCV-AND). This is mostly independent of liver derangement, as disclosed by the comparison with NAFLDs. Therefore, it must be ascribed to the direct or indirect effects of the viral infection onto the brain. Viral clearance through DAAs implies a cognitive improvement in given functional domains. The P300 wave can document these changes. DAAs may thus have a role in the early preservation of higher-order neural abilities in HCVs.

Funding This study was funded by the "AGING Project - Department of Excellence -" from the Department of Translational Medicine, University of Piemonte Orientale, Novara, Italy. Open access funding provided by Università degli Studi del Piemonte Orientale Amedeo Avogrado within the CRUI-CARE Agreement.

\section{Compliance with ethical standards}

Conflict of interest/competing interests The authors declare that they have no conflicts of interest.

Ethics approval "Maggiore della Carità" Hospital, Novara, Italy, Ethics Committee. Approval \# RQ07117.

Consent to participate Written informed consent provided by all subjects (see "Methods"). 
Consent for publication Included in the informed consent

\section{Appendix}

In all $\mathrm{HCV}$ patients, treatment with direct-acting antiviral agents (DAAs) lasted 12 weeks. The drugs used were elbasvir/grazoprevir $50 \mathrm{mg} / 100 \mathrm{mg}$ (Zepatier®) (11 patients); sofosbuvir/velpatasvir $400 \mathrm{mg} / 100 \mathrm{mg}$ (Epclusa®) (8 patients); ombitasvir/paritaprevir/ ritonavir $12.5 \mathrm{mg} / 75 \mathrm{mg} /$ $50 \mathrm{mg}+$ dasabuvir $250 \mathrm{mg}$ (Viekirax ${ }^{\circledR}+$ Exviera $\AA$ ) (3 patients); daclatasvir/sofosbuvir $60 \mathrm{mg}$ (Daklinza $®+$ sofosbuvir) (1 patient).

Open Access This article is licensed under a Creative Commons Attribution 4.0 International License, which permits use, sharing, adaptation, distribution and reproduction in any medium or format, as long as you give appropriate credit to the original author(s) and the source, provide a link to the Creative Commons licence, and indicate if changes were made. The images or other third party material in this article are included in the article's Creative Commons licence, unless indicated otherwise in a credit line to the material. If material is not included in the article's Creative Commons licence and your intended use is not permitted by statutory regulation or exceeds the permitted use, you will need to obtain permission directly from the copyright holder. To view a copy of this licence, visit http://creativecommons.org/licenses/by/4.0/.

\section{References}

Amodio P, Montagnese S (2015) Clinical neurophysiology of hepatic encephalopathy. J Clin Exp Hepatol 5:S60-S68

Amodio P, Valenti P, Del Piccolo F, Pellegrini A, Schiff S, Angeli P, Poci C, Mapelli D, Iannizzi P, Gatta A (2005) P300 latency for the diagnosis of minimal hepatic encephalopathy: evidence that spectral EEG analysis and psychometric tests are enough. Dig Liver Dis 37:861-868

Borkowski JG, Benton AL, Spreen O (1967) Word fluency and brain damage. Neuropsychologia 5:135-140

Byrnes V, Miller A, Lowry D, Hill E, Weinstein C, Alsop D, Lenkinski R, Afdhal NH (2012) Effects of anti-viral therapy and HCV clearance on cerebral metabolism and cognition. J Hepatol 56:549-556

Child CG, Turcotte JG (1964) Surgery and portal hypertension. Major Probl Clin Surg 1:1-85

Chalasani N, Younossi Z, Lavine JE, Charlton M, Cusi K, Rinella M, Harrison SA, Brunt EM, Sanyal AJ (2018) The diagnosis and management of nonalcoholic fatty liver disease: practice guidance from the American Association for the Study of Liver Diseases. Hepatology 67:328-357

Chen J, Florian J, Carter W, Fleischer RD, Hammerstrom TS, Jadhav PR, Zeng W, Murray J, Birnkrant D (2013) Earlier sustained virologic response end points for regulatory approval and dose selection of hepatitis C therapies. Gastroenterology 144:1450-1455

Diamond A (2013) Executive functions. Annu Rev Psychol 64:135-168

Dirks M, Pflugrad H, Haag K, Tillmann HL, Wedemeyer H, Arvanitis D, Hecker H, Tountopoulou A, Goldbecker A, Worthmann H, Weissenborn K (2017) Persistent neuropsychiatric impairment in HCV patients despite clearance of the virus?! J Viral Hepat 24: $541-550$

Duncan CC, Barry RJ, Connolly JF, Fischer C, Michie PT, Näätänen R, Polich J, Reinvang I, Van Petten C (2009) Event-related potentials in clinical research: guidelines for eliciting, recording, and quantifying mismatch negativity, P300, and N400. Clin Neurophysiol 120:1883-1908

Fath-Elbab HK, Ahmed E, Mansour DF, Soliman WT (2018) Eventrelated evoked potential versus clinical tests in assessment of subclinical cognitive impairment in chronic hepatitis $\mathrm{C}$ virus. Egypt $\mathrm{J}$ Neurol Psychiatry Neurosurg 54:35

Folstein MF, Folstein SE, McHugh PR (1975) "Mini-mental state". A practical method for grading the cognitive state of patients for the clinician. J Psychiatr Res 12:189-198

Fontana RJ, Bieliauskas LA, Back-Madruga C, Lindsay KL, Kronfol Z, Lok AS, Padmanabhan L, HALT-C Trial Group (2005) Cognitive function in hepatitis $\mathrm{C}$ patients with advanced fibrosis enrolled in the HALT-C trial. J Hepatol 43:614-622

Fortini I, Arouca EMG, Tengam FM, Nitrini R (2019) Chronic HCV infection and neuropsychiatric dysfunction. eNeurologicalSci 17: 100206

Guerit JM, Amantini A, Fischer C, Kaplan PW, Mecarelli O, Schnitzler A, Ubiali E, Amodio P, members of the ISHEN commission on Neurophysiological Investigations (2009) Neurophysiological investigations of hepatic encephalopathy: ISHEN practice guidelines. Liver Int 29:789-796

Spinnler H, Tognoni G (1987) Italian standardization and classification of neuropsychological tests. Ital J Neurol Sci 6:1-120

Hamdy HSE, Abd El Hamid MSE, Shafik MA, Soliman EMAM (2018) Impact of direct acting antiviral drugs (DAADs) on cognitive function among hepatitis $\mathrm{C}$ virus infected patients. Egypt J Hosp Med 73:5743-5747

Heeren M, Weissenborn K, Arvanitis D, Bokemeyer M, Goldbecker A, Tountopoulou A, Peschel T, Grosskreutz J, Hecker H, Buchert R, Berding G (2011) Cerebral glucose utilisation in hepatitis C virus infection-associated encephalopathy. J Cereb Blood Flow Metab 31: 2199-2208

Hilsabeck RC, Perry W, Hassanein TI (2002) Neuropsychological impairment in patients with chronic hepatitis C. Hepatology 35:440 446

Huckans M, Seelye A, Parcel T, Mull L, Woodhouse J, Bjornson D, Fuller BE, Loftis JM, Morasco BJ, Sasaki AW, Storzbach D, Hauser P (2009) The cognitive effects of hepatitis $C$ in the presence and absence of a history of substance use disorder. $\mathrm{J}$ Int Neuropsychol Soc 15:69-82

Juanbeltz R, Martínez-Baz I, San Miguel R, Goñi-Esarte S, Cabasés JM, Castilla J (2018) Impact of successful treatment with directacting antiviral agents on health-related quality of life in chronic hepatitis C patients. PLoS One 13:e0205277

Kleefeld F, Heller S, Ingiliz P, Jessen H, Petersen A, Kopp U, Kraft A, Hahn K (2018) Interferon-free therapy in hepatitis C virus (HCV) monoinfected and $\mathrm{HCV} / \mathrm{HIV}$ coinfected patients: effect on cognitive function, fatigue, and mental health. J Neuro-Oncol 24:557-569

Kramer L, Bauer E, Funk G, Hofer H, Jessner W, Steindl-Munda P, Wrba F, Madl C, Gangl A, Ferenci P (2002) Subclinical impairment of brain function in chronic hepatitis C infection. J Hepatol 37:349354

Kraus MR, Schäfer A, Teuber G, Porst H, Sprinzl K, Wollschläger S, Keicher C, Scheurlen M (2013) Improvement of neurocognitive function in responders to an antiviral therapy for chronic hepatitis C. Hepatology 58:497-504

Letendre S, Paulino AD, Rockenstein E, Adame A, Crews L, Cherner M, Heaton R, Ellis R, Everall IP, Grant I, Masliah E, HIV Neurobehavioral Research Center Group (2007) Pathogenesis of hepatitis $\mathrm{C}$ virus coinfection in the brains of patients infected with HIV. J Infect Dis 196:361-370

Lowry D, Coughlan B, McCarthy O, Crowe J (2010) Investigating health-related quality of life, mood and neuropsychological test performance in a homogeneous cohort of Irish female hepatitis $\mathrm{C}$ patients. J Viral Hepat 17:352-359 
Marra C, Ferraccioli M, Gainotti G (2007) Gender-related dissociations of categorical fluency in normal subjects and in subjects with Alzheimer's disease. Neuropsychology 21:207-211

McAndrews MP, Farcnik K, Carlen P, Damyanovich A, Mrkonjic M, Jones S, Heathcote EJ (2005) Prevalence and significance of neurocognitive dysfunction in hepatitis $\mathrm{C}$ in the absence of correlated risk factors. Hepatology 41:801-808

Monaco S, Mariotto S, Ferrari S, Calabrese M, Zanusso G, Gajofatto A, Sansonno D, Dammacco F (2015) Hepatitis C virus-associated neurocognitive and neuropsychiatric disorders: advances in 2015. World J Gastroenterol 21:11974-11983

Osterrieth PA (1944) Filetest de copie d'une figure complex: contribution a l'etude de la perception et de la memoire [the test of copying a complex figure: a contribution to the study of perception and memory]. Arch Psychol (Geneve) 30:286-356

Pecoraro V, Banzi R, Cariani E, Chester J, Villa E, D'Amico R, Bertele V, Trenti T (2019) New direct-acting antivirals for the treatment of patients with hepatitis $\mathrm{C}$ virus infection: a systematic review of randomized controlled trials. J Clin Exp Hepatol 9:522-538

Picton TW (1992) The P300 wave of the human event-related potential. J Clin Neurophysiol 9:456-479

Rey A (1964) L'examen clinique en psychologie. Presses universitaires de France, Paris

Thames AD, Castellon SA, Singer EJ, Nagarajan R, Sarma MK, Smith J, Thaler NS, Truong JH, Schonfeld D, Thomas MA, Hinkin CH (2015) Neuroimaging abnormalities, neurocognitive function, and fatigue in patients with hepatitis C. Neurol Neuroimmunol Neuroinflamm 2:e59

Thein HH, Maruff P, Krahn MD, Kaldor JM, Koorey DJ, Brew BJ, Dore GJ (2007) Improved cognitive function as a consequence of hepatitis $\mathrm{C}$ virus treatment. HIV Med 8:520-528
Volpato S, Montagnese S, Zanetto A, Turco M, De Rui M, Ferrarese A, Amodio P, Germani G, Senzolo M, Gambato M, Russo FP, Burra P (2017) Neuropsychiatric performance and treatment of hepatitis C with direct-acting antivirals: a prospective study. BMJ Open Gastroenterol 4:e000183

Wechsler D (1958) The measurement and appraisal of adult intelligence, 4 th edn. William \& Wilkins, Baltimore

Weissenborn K (2015) Diagnosis of minimal hepatic encephalopathy. J Clin Exp Hepatol 5:S54-S59

Weissenborn K, Ennen JC, Bokemeyer M, Ahl B, Wurster U, Tillmann H, Trebst C, Hecker H, Berding G (2006) Monoaminergic neurotransmission is altered in hepatitis $C$ virus infected patients with chronic fatigue and cognitive impairment. Gut 55:1624-1630

Weissenborn K, Ennen JC, Schomerus H, Rückert N, Hecker H (2001) Neuropsychological characterization of hepatic encephalopathy. J Hepatol 34:768-773

Wijdicks EFM (2016) Hepatic encephalopathy. N Engl J Med 375:16601670

Yarlott L, Heald E, Forton D (2017) Hepatitis C virus infection, and neurological and psychiatric disorders - a review. J Adv Res 8: 139-148

Yeoh SW, Holmes ACN, Saling MM, Everall IP, Nicoll AJ (2018) Depression, fatigue and neurocognitive deficits in chronic hepatitis C. Hepatol Int 12:294-304

Publisher's note Springer Nature remains neutral with regard to jurisdictional claims in published maps and institutional affiliations. 